\title{
Study of the pitting corrosion at welding joints of Inconel 625 alloy under high temperature and high $\mathrm{H}_{2} \mathrm{~S} / \mathrm{CO}_{2}$ partial pressure
}

Qiang Guo ${ }^{1,2}$, Yuan $\mathrm{Li}^{1,2}$, Jiong Qian ${ }^{1,2}$, Haobo $\mathrm{Yu}^{1,2}$, Changfeng Chen ${ }^{1,2, *}$

${ }^{1}$ College of Mechanical and Electrical Engineering, China University of Petroleum (Beijing), No.18 FuXue road, ChangPing district, Beijing, 102249, China

${ }^{2}$ Beijing Key Laboratory of Failure, Corrosion and Protection of Oil/gas Facilities, China University of Petroleum (Beijing), Changping District, Fuxue Road 18, Beijing 102249, P. R. China.

*E-mail: tyhb_yu@163.com

doi: $10.20964 / 2017.10 .46$

Received: 19 March 2017 / Accepted: 6 August 2017 / Published: 12 September 2017

The corrosion resistances of the Incoloy 825 alloy base metal and the Inconel 625 alloy weld under high temperature high pressure (HTHP) $\mathrm{H}_{2} \mathrm{~S} / \mathrm{CO}_{2}$ conditions were investigated. Pitting was only presented on the Inconel 625 alloy weld, even though it contains more corrosion-resistant elements than the Incoloy 825 alloy. Laves and $G$ phases were found in the 625 alloy weld, which were confirmed to possess a lower corrosion resistance than the matrix using scanning Kelvin probe force microscopy. The changes in the semiconductor structure of the passive films were analysed through the Mott-Schottky curves after the HTHP $\mathrm{H}_{2} \mathrm{~S} / \mathrm{CO}_{2}$ corrosion. Finally, the pitting mechanism of Inconel 625 weld was discussed.

Keywords: $\mathrm{G}$ phase, Laves phase, Mott-Schottky plot, Pitting corrosion, $\mathrm{H}_{2} \mathrm{~S} / \mathrm{CO}_{2}$ corrosion

\section{FULL TEXT}

(C) 2017 The Authors. Published by ESG (www.electrochemsci.org). This article is an open access article distributed under the terms and conditions of the Creative Commons Attribution license (http://creativecommons.org/licenses/by/4.0/). 